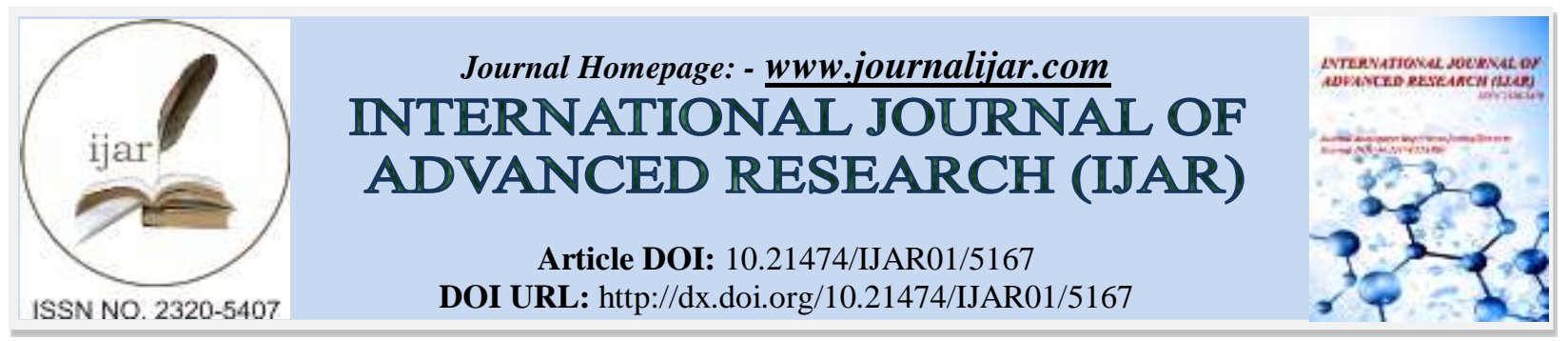

RESEARCH ARTICLE

\title{
CHITOSAN- CIPROFLOXACIN SCHIFF BASES: SYNTHESIS, CHARACTERIZATION AND IN VITROANTIMICROBIAL ACTIVITY EVALUATION.
}

\begin{abstract}
*Emad A. Soliman ${ }^{1}$, Ahmed I. Hashem ${ }^{2}$ and Ahmed R. Abou-zeid ${ }^{1}$.
1. Department of Polymeric Materials Research, Advanced Technology and New Materials Research Institute, City of Scientific Research and Technology Applications, New Borg El-Arab City, 21934, Alex., Egypt.

2. Department of Chemistry, Faculty of Science, Ain Shams University, El-Abassia, Cairo, Egypt.
\end{abstract}

Manuscript Info
Manuscript History
Received: 14 June 2017
Pinal Accepted: 16 July 2017
Key words:-
Chitosan; Ciprofloxacin; Schiff bases;
Antimicrobial activity.

Antimicrobial activity.

\begin{abstract}
In the present work, chitosan-ciprofloxacin Schiff bases (CHS-CFXSB) containing azomethine group $(-\mathrm{CH}=\mathrm{N}-$ ) have been synthesized via condensing amino groups $\left(\mathrm{NH}_{2}\right)$ of chitosan and carbonyl group (CO) of ciprofloxacin by using different molar ratios $(0.05,0.1,0.25,0.5$ and 1) to enhance the antimicrobial activity of ciprofloxacin to offer a great potential for medical applications. The obtained CHS-CFX-SBs were structurally characterized using FT-IR and ${ }^{1} \mathrm{H}$ NMR spectral analysis. Thus, the antimicrobial activities of these Schiff bases were assessed against six bacterial species, three gram-positive species (Methicillin resistant Staphylococcus aureus (MRSA), Streptococcus pyogenus and Streptococcus pneumoniae) and three gram-negative species (Escherichia coli, Klebsiella pneumonia and Pseudomonas aeruginosa) and one of fungus species; Candida albican by determining the microbial growth by measuring the inhibition zones in $\mathrm{mm}$. The findings of this assessment showed that CHS-CFX-SB prepared by using equal molar ratio is having higher antibacterial activity against gram-positive bacteria than gram-negative ones. And thus, these chitosan derivatives have strong antibacterial activity against Staphylococcus aureus. Such Schiff bases had higher inhibitory efficiency against gram-positive bacteria than that of ciprofloxacin itself.
\end{abstract}

Copy Right, IJAR, 2017,. All rights reserved.

\section{Introduction:-}

Microbial infection the main cause of death of human worldwide and thus serious limitations and disadvantages of low molecular weight organic antimicrobial agents including antibiotics, such as cytotoxicity and short-term acting, in addition to emergence of the antibiotic resistant strains make development of new desirable antimicrobial agents is a vital issue in the present time, thence theantimicrobial polymer materials can be considered one of the most promising way for minimizing the environmental problems by reducing the residual toxicity of the conventional antimicrobial agents, increasing their efficiency and selectivity, and prolonging their lifetime[1].

Moreover, the use of such materials offers promise for rendering biomaterials resistance towards microorganisms that is a definite need in several areas, particularly in medical devices, drugs, health care and hygienic applications, water purification systems, hospital and dental surgery equipment, textiles, food preservation and packaging.

Corresponding Author:- Emad A. Soliman

Address:- Department of Polymeric Materials Research, Advanced Technology and New Materials 
Ciprofloxacin hydrochloride belongs to the second generation broad-spectrum fluoroquinolone antibiotic used to treat various bacterial infections. Fluoroquinolones target bacterial DNA gyrase, a type II topoisomerase in gram negative bacteria and topoisomerase IV in gram positive bacteria, an enzyme active in the process of DNA supercoiling, which allows the DNA strands within the bacterial cell to be compacted in an orderly fashion [2].

Inhibition of DNA gyrase permits the DNA strands to become entangled, thus preventing DNA replication, transcription, recombination, and repair, and resulting in bacterial death. It is highly active against various grampositive and gram-negative bacteria [3].

Ciprofloxacin is used for the treatment of urinary tract infections, prostatitis, continuous ambulatory peritoneal dialysis infections, skin and skin infections, bone and joint infections, some diabetic foot infection, typhoid fever, etc. It shows anti-tumor activity against P388 leukemia [4]. However, relatively short serum half-life and certain adverse effects of ciprofloxacin, such as CNS effects, phototoxicity, tendonitis, hypoglycemia, and serious cardiac dysrhythmias are considered limiting factors for therapeutic potential of CFX 3-4 [5-8].

Recently, due to the increased resistance of some infections to ciprofloxacin, several trials were performed to modify the functional groups in this antibiotic to enhance its antimicrobial activity [9-18].

On the other hand, extremely potent activity and rapid bactericidal effects open the door for chitosan to be employed as contact disinfectants and sterile materials in many biomedical applications. Chitosan molecule bears free amino groups at C-2 position which can allow chemical substitution reactions to get various derivatives with a large spectrum of applications. Among these derivatives, chitosan Schiff-base which can be obtained by the reaction of these free amino groups of chitosan with active carbonyl compounds such as aldehyde or ketone with the created imine group $(-\mathrm{RC}=\mathrm{N}-)$ on the Schiff-base product, these Schiff bases offer several biomedical applications [18-26] In the light of excellent antimicrobial activities of ciprofloxacin and chitosan, the present study enlightens the development of polymeric materials with biocide activity via synthesis of chitosan-ciprofloxacin Schiff bases with their structural characterization by using spectroscopic analyses including IR and ${ }^{1} \mathrm{HNMR}$ and evaluation of their invitro antimicrobial activities.

\section{Materials and Methods:-}

Chitosan (CHS, $M \eta=620 \mathrm{kDa}$, degree of deacetylation $=85 \%$, viscosity $=115 \mathrm{cps}$ ) is a commercial product of from Acros Organics, New Jersey, USA. Ciprofloxacin hydrochloride (CFX, C17H18FN3O3.HCl.H2O) was purchased from Pharco company for pharmaceutical industry (Alexandria, Egypt). Glacial acetic acid was purchased from Alpha Chemika, Mumbai, India. All other chemicals were of analytical grade and used as received. The water used in all experiments was triple distilled.

Preparation of ciprofloxacin-chitosan Schiff bases:-

One gram of chitosan (5.6 mmole of glucosamine unit) was dissolved in $200 \mathrm{ml}$ of $1 \% \mathrm{AcOH}$ with stirring until forming a clear solution. Ciprofloxacin hydrochloride was added to chitosan at different molar ratios $(0.05,0.1$, $0.25,0.5$ and 1) where, certain weight of CFX was dissolved in distilled water and then,aliquotsfrom this solution were added dropwise to the previously prepared chitosan solution with heatingat $55^{\circ} \mathrm{C}$ for 24 hours. The resultant precipitate was filtered off and dried at $50{ }^{\circ} \mathrm{C}$ (scheme 1). 

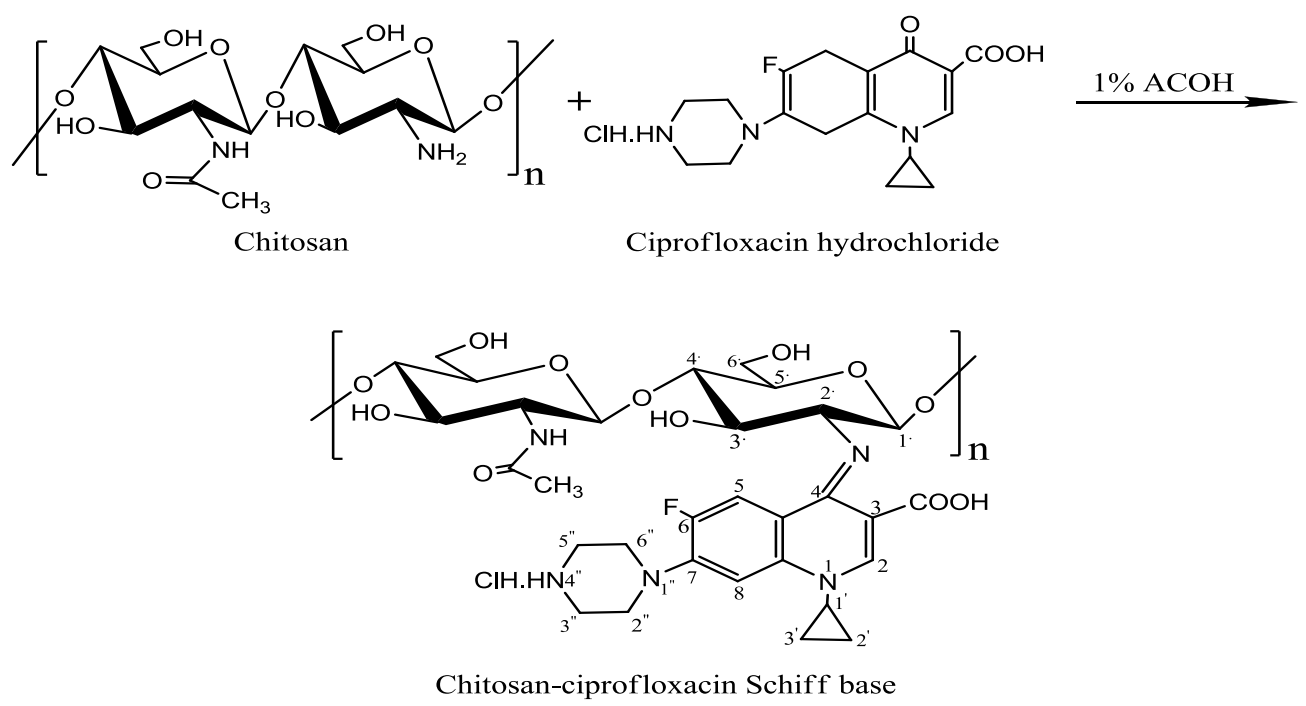

\section{Spectral analysis:-}

Scheme 1:- Chitosan-ciprofloxacin Schiff bases preparation.

\section{FT-IR:-}

FT-IR spectroscopic analysis were performed for ciprofloxacin, chitosan and chitosan-derived Schiff bases (Shimadzu, Japan) after their preparation in form of $\mathrm{KBr}$ pellets usingShimadzu 8400S FTIR spectrometer. The crushed samples $(\sim 4 \mathrm{mg})$ were mixed with $200 \mathrm{mg}$ of potassium bromide and was further ground in an agate mortar with pestle. The mixture was then transferred to a die and pressed into a disc in a vacuum press at $80 \mathrm{KN}$. The FTIR spectra were collected over the frequency range of 400-4000 cm-1. These spectra were Fourier-deconvoluted for 128interferograms with a resolution enhancement factor of 2 and a bandwidth of $15 \mathrm{~cm}-1$ at room temperature and presented in absorption mode after the baseline correction [27].

\section{H NMR}

${ }^{1} \mathrm{H}$ NMR spectroscopic analysis were carried outat 500.2 MHz using JEOL 500 MH NMR spectrometer (JEOL, Japan). Samples dissolved in DMSO/TFA were analyzed by a dual probe head at $25^{\circ} \mathrm{C}$. The spectra were accumulated into $32 \mathrm{~K}$ data points and processed using exponential multiplication with $2 \mathrm{~Hz}$ line broadening into $128 \mathrm{~K}$ spectra. For the resulting spectra 25000-35000 scans were accumulated. All spectra were accumulated under identical conditions using power gated Waltz decoupling with 25-degree measurement pulse and 1s prepulse delay [28].

\section{In Vitro antimicrobial assays:-}

Antimicrobial activity of chitosan, ciprofloxacin and their derived Schiff bases were assessed against six bacterial strains, three gram-positive species (Staphylococcus aureus, Streptococcus pyogenus and Streptococcuspneumonia), three gram-negative bacteria (Escherichia coli, Klebsiella pneumonia and Pseudomonas aeruginosa) and one fungi species Candida albican. These strains are common contaminates of the environment in Egypt and some of which are involved in human and animal diseases. All microbial strains were kindly provided by Ain Shams University Microbiology Center (ASMC).

Bacterial strains were individually cultured for $48 \mathrm{~h}$ in $100 \mathrm{ml}$ conical flasks containing $30 \mathrm{ml}$ nutrient broth medium. Fungi were grown for 7 days in $100 \mathrm{ml}$ conical containing $30 \mathrm{ml}$ Sabouraud's dextrose broth. One milliliter of cultured microbial suspension was added into tube containing mixture of $10 \mathrm{ml}$ of broth culture medium presterilized by autoclaving at $121^{\circ} \mathrm{C}$ for $15 \mathrm{~min}$ and $2 \mathrm{ml}$ of chitosan, ciprofloxacin or Schiff bases solution $(0.5 \%$ in an aqueous acetic solution $(0.5 \%)$. These tubes containing bacterial or fungal strains were incubated in shaking incubator at $37^{\circ} \mathrm{C}$ for 24 or $48 \mathrm{~h}$, respectively. The growth of these organism strains in the presence of ciprofloxacin and its Schiff bases was detected by disc diffusion method [29]. 


\section{Preparation of Agar Plates:- For antibacterial test:-}

$10 \mathrm{~g}$ peptone, $10 \mathrm{~g}$ sodium chloride, $5 \mathrm{~g}$ yeast extract and $15 \mathrm{~g}$ agar were dissolved properly in $1000 \mathrm{ml}$ distilled water in $1000 \mathrm{ml}$ conical flask with stirring. Then mouth of conical flask was plugged with cotton. Conical flask was put in autoclave for sterilization for $15 \mathrm{lbs}$ for $20 \mathrm{~min}$. After autoclaving, warm 20-25 ml media was poured on Petri dish per plate in front of laminar flow. Leave it until media were solidified in Petri dish. Now agar plate was ready for use.

\section{For antifungal test:-}

$5 \mathrm{~g}$ glucose, $5 \mathrm{~g}$ peptone, $2.5 \mathrm{~g}$ yeast extract and $4 \mathrm{~g}$ agar were dissolved properly in $250 \mathrm{ml}$ distilled water in $250 \mathrm{ml}$ conical flask with stirring. Then mouth of conical flask was plugged with cotton. Conical flask was put in autoclave for sterilization for $15 \mathrm{lbs}$ for $20 \mathrm{~min}$. After autoclaving, warm 20-25 ml media was poured on Petri dish per plate in front of laminar flow. Leave it until media were solidified in Petri dish. Now agar plates were ready for use.

\section{Preparation of Compounds Solution:-}

Ciprofloxacin and the five synthesized Schiff bases were dissolved in aqueous solution of $0.5 \%$ aceticacid in test tube with vertex stirring, heated if required (each material was prepared at these concentrations 10, 15, 20 and 25 $\mu \mathrm{g} / \mathrm{ml}$ ) given the code of each tube. Divided the bottom of prepared plate into four quadrants with the help of marker. Given the same code to each quadrant as given to code to test tube containing solution of compound. Swab the one plate from one bacterial suspension with the help of cotton swab, coded the name of bacteria on each plate. Same procedure was adopted for all plates. With the help of micro pipette ,10, 15, 20 and $25 \mu \mathrm{g} / \mathrm{ml}$ solution of compound was dropped on same code of quadrant as given on the test tube containing solution of compound. Same procedure was adopted for all compounds in laminar flow. All plates were put in incubator for incubation for 24 hrs. After $24 \mathrm{hrs}$, view the plate. If the specific compound was sensitive for specific bacteria. Then growth was found in whole plate except where solution of compound was dropped. If the specific compound was not sensitive for specific bacteria. Then growth was found in whole plate including where solution of compound was dropped.

\section{Results and Discussions:- FT-IR spectral analysis:-}

FTIR spectra of ciprofloxacin, chitosan and ciprofloxacin-chitosan based Schiff bases are presented in (figure 1). Ciprofloxacin spectrum exhibited two prominent super imposed characteristic peaks at 3514 and $3400 \mathrm{~cm}^{-1}$ which were assigned to the stretching vibration of $\mathrm{O}-\mathrm{H}$ (of the carboxylic group at $\mathrm{C}_{3}$ position) and $\mathrm{N}-\mathrm{H}$ groups respectively, another band at $3064 \mathrm{~cm}^{-1}$ represented the alkene and aromatic $\mathrm{C}-\mathrm{H}$ stretching vibration. The band at $1676 \mathrm{~cm}^{-1}$ represented the carbonyl $\mathrm{C}=\mathrm{O}$ stretching vibration, the band at $1471 \mathrm{~cm}^{-1}$ represented $\mathrm{C}-\mathrm{O}$ stretching vibration and at $1303 \mathrm{~cm}^{-1}$ suggested bending vibration of $\mathrm{O}-\mathrm{H}$ group. A strong absorption peak at $985 \mathrm{~cm}^{-1}$ was assigned to C-F group. The IR spectrum of chitosan : $3427 \mathrm{~cm}^{-1}$ ( O-H stretching overlapping the N-H stretching ), $2902 \mathrm{~cm}^{-1}$ ( C-H aliphatic stretching vibration ), $1627 \mathrm{~cm}^{-1}$ (amide $\mathrm{C}=\mathrm{O}, \mathrm{C}-\mathrm{O}$ stretching of the acetyl group ), $1402 \mathrm{~cm}^{-1}$ (asymmetrical C-H bending of the $\mathrm{CH}_{2}$ group). The peak appeared at $1060 \mathrm{~cm}^{-1}$ is the characteristic peak due to stretching of $\mathrm{C}-\mathrm{O}$ pairing in $\beta(1 \rightarrow 4)$ glycosidic bonds of polysaccharide. However, the IR spectra of ciprofloxacin-chitosan Schiff bases (Figure 1) showed strong characteristic absorption peaks at 1618, 1600, 1598, 1608 and $1577 \mathrm{~cm}^{-1}$ are attributed to the vibration of $\mathrm{C}=\mathrm{N}$ of imines formed in the condensation reaction of ciprofloxacin and with the molar ratios $(0.05,0.1,0.25,0.5$ and 1$)$ respectively. Further peaks appeared at the range from 1000 to $1100 \mathrm{~cm}^{-1}$ are attributed to the characteristic stretching of $\mathrm{C}-\mathrm{O}$ pairing in $\beta(1 \rightarrow 4)$ glycosidic bonds of polysaccharides. 


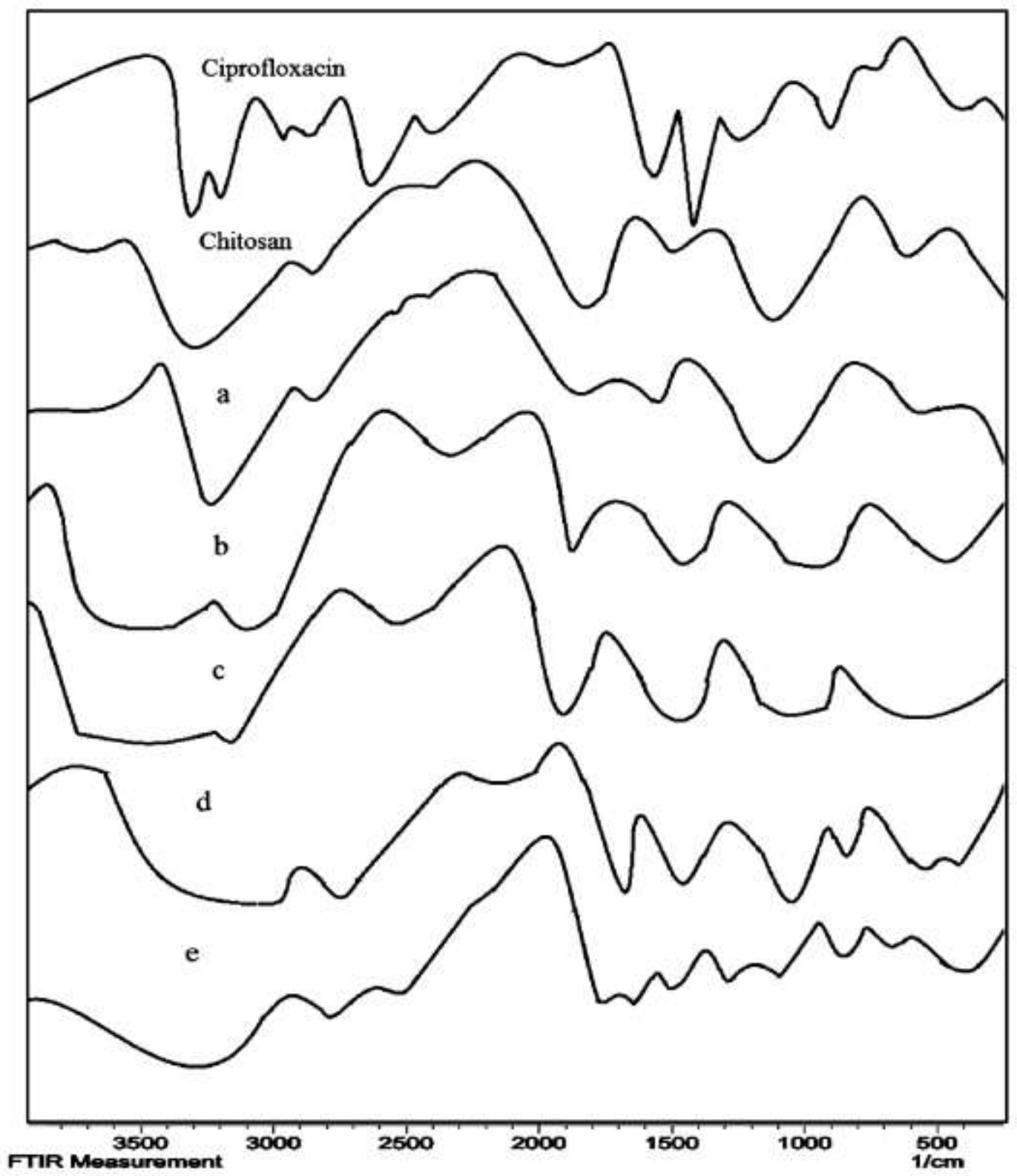

Figure 1:- FTIR spectra of ciprofloxacin, chitosan, derived Schiff bases; a,b,c,d and e synthesized with ciprofloxacin/chitosan at molar ratios of (0.05:1), (0.1:1), (0.25:1), (0.5:1) and (1:1) respectively.

\section{${ }^{1}$ H NMR spectral analysis:-}

The chemical modification of ciprofloxacin can be obviously confirmed by ${ }^{1} \mathrm{H}$ NMR spectroscopy. The ${ }^{1} \mathrm{H}$ NMR signals of the synthesized ciprofloxacin-chitosan Schiff bases compared with ciprofloxacin and chitosan are shown in (figure 2). 


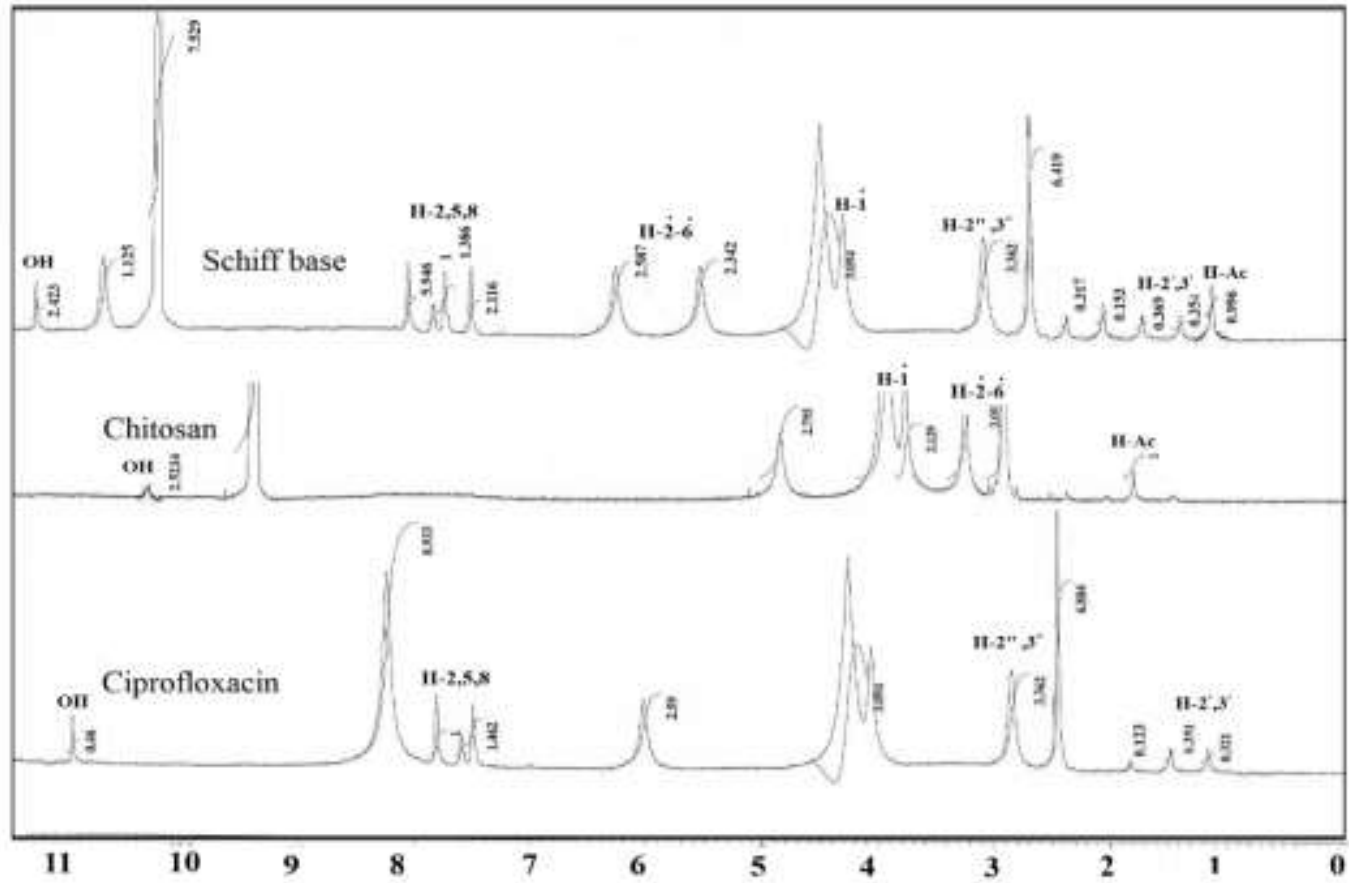

Figure 2:- ${ }^{1} \mathrm{H}$ NMR spectra of ciprofloxacin, chitosan and the corresponding Schiff base.

${ }^{1}$ H NMR spectra of ciprofloxacin, chitosan and the corresponding Schiff bases are shown in (figure 2). In all cases, the peaks attributed to the protons along the backbones of ciprofloxacin and chitosan are numbered in (figure 2). The 3 proton assignments of ciprofloxacin were: 1.1-1.5 ppm (H-2,3), 2.5-2.9 ppm (H-2",3") and 7-8 ppm (H-2,5,8). The proton assignments of chitosan were: $1.2 \mathrm{ppm}\left(\mathrm{CH}_{3}\right.$ of the acetyl group), 2.5-3.6 ppm (H-2-6. of glucosamine ring) and $4.7 \mathrm{ppm}\left(\mathrm{H}-1^{\circ}\right)$. The proton assignments of the synthesized Schiff base were: $0.9 \mathrm{ppm}\left(\mathrm{CH}_{3}\right.$ of the acetyl group), 1.2-1.5 ppm (H-2,3), 2.4-2.9 ppm (H-2",3"), $5.3 \mathrm{ppm}\left(\mathrm{H}-1^{\circ}\right), 5.4-6.3 \mathrm{ppm}\left(\mathrm{H}-2^{\circ}-6^{\circ}\right.$ of glucosamine ring) and 7-8 ppm $(\mathrm{H}-2,5,8)$.

The degree of substitution determination was based on the ratio of the areas of the aromatic protons $(\mathrm{H}-2,5,8)$ to the proton of the pyranose ring $(\mathrm{H}-2)$, as presented in the following equation:

$D S(\%)=\left(A_{\text {aromatic }} / \mathrm{A}_{\mathrm{H}-2}\right) \times 100$

where ;

$D S=$ Degree of substitution.

$A_{\text {imine }}=$ Area of aromatic protons peak .

$A_{\mathrm{H}-2}=$ Area of $\mathrm{H}-2$ proton peak of the pyranose ring.

DS values were calculated using the aforementioned equation. These results that presented in table 2 indicated that DS values ranged from 15.6 to $42.7 \%$. Moreover, it was indicated that degrees of substitution for all types of chitosan Schiff bases were close to each other. However, the yield of this process was calculated using the following equation:

Process yield $(\%)=$ Product $($ Schiff base) weight $/$ reactants $($ chitosan + ciprofloxacin) weight $\times 100$

The calculated yield values were tabulated in (table 1.) These values ranged from 72.9 to $85.0 \%$ based on the ratio of ciprofloxacin to chitosan and the degree of substitution.

Table 1: Substitution degree and yield of chitosan-ciprofloxacin Schiff bases.

\begin{tabular}{|l|c|c|}
\hline Chitosan-ciprofloxacin Schiff base & DS \% & Yield \% \\
\hline SB.1 & 15.6 & 72.9 \\
\hline SB.2 & 18.5 & 74.1 \\
\hline
\end{tabular}




\begin{tabular}{|l|c|c|}
\hline SB.3 & 20.8 & 72.7 \\
\hline SB.4 & 23.3 & 83.0 \\
\hline SB.5 & 42.7 & 85.0 \\
\hline
\end{tabular}

Antimicrobial activity:-

The antimicrobial activities of the five Schiff's bases obtained in this study were evaluated using six bacterial strains. (cf. the experimental part). The results of this evaluation are compared with the activities of ciprofloxacin and chitosan itself were recorded in table 2.

Table 2:- Zone of inhibition (mm) of ciprofloxacin and their derivatives against various microorganisms.

\begin{tabular}{|l|l|l|l|l|l|l|l|l|l|l|l|l|l|l|l|l|}
\hline Organisms & \multicolumn{4}{|c|}{ CFX. } & \multicolumn{4}{|c|}{ CHS. } & \multicolumn{3}{|c|}{ SB.1 } & \multicolumn{3}{|c|}{ SB.2 } \\
\hline ( $\boldsymbol{\mu \text { g/ml) }}$ & $\mathbf{1 0}$ & $\mathbf{1 5}$ & $\mathbf{2 0}$ & $\mathbf{2 5}$ & $\mathbf{1 0}$ & $\mathbf{1 5}$ & $\mathbf{2 0}$ & $\mathbf{2 5}$ & $\mathbf{1 0}$ & $\mathbf{1 5}$ & $\mathbf{2 0}$ & $\mathbf{2 5}$ & $\mathbf{1 0}$ & $\mathbf{1 5}$ & $\mathbf{2 0}$ & $\mathbf{2 5}$ \\
\hline S. aureus & 10 & 12 & 14 & 16 & 5 & 8 & 9 & 12 & 8 & 12 & 14 & 15 & 10 & 11 & 19 & 22 \\
\hline S.pyogenus & 8 & 10 & 12 & 13 & 10 & 12 & 13 & 16 & 5 & 8 & 10 & 15 & 8 & 10 & 12 & 14 \\
\hline S. pneumoniae & 10 & 12 & 13 & 15 & 6 & 9 & 12 & 14 & 8 & 10 & 13 & 15 & 9 & 12 & 15 & 18 \\
\hline E. coli & 15 & 18 & 20 & 22 & 0 & 5 & 8 & 10 & 6 & 10 & 12 & 18 & 5 & 8 & 13 & 16 \\
\hline K. pneumoniae & 12 & 14 & 15 & 18 & 0 & 4 & 8 & 10 & 8 & 12 & 15 & 18 & 6 & 10 & 12 & 16 \\
\hline P.aeruginosa & 12 & 14 & 15 & 18 & 0 & 7 & 10 & 13 & 6 & 10 & 14 & 18 & 5 & 8 & 12 & 15 \\
\hline
\end{tabular}

\begin{tabular}{|l|l|l|l|l|l|l|l|l|l|l|l|}
\hline \multicolumn{4}{|c|}{ SB.3 } & \multicolumn{9}{c|}{ SB.4 } & \multicolumn{4}{c|}{ SB.5 } \\
\hline $\mathbf{1 0}$ & $\mathbf{1 5}$ & $\mathbf{2 0}$ & $\mathbf{2 5}$ & $\mathbf{1 5}$ & $\mathbf{1 0}$ & $\mathbf{2 0}$ & $\mathbf{2 5}$ & $\mathbf{1 0}$ & $\mathbf{1 5}$ & $\mathbf{2 0}$ & $\mathbf{2 5}$ \\
\hline 8 & 10 & 15 & 18 & 14 & 19 & 20 & 24 & 18 & 24 & 28 & 33 \\
\hline 5 & 10 & 13 & 16 & 5 & 10 & 12 & 14 & 10 & 15 & 22 & 27 \\
\hline 5 & 10 & 12 & 15 & 8 & 13 & 18 & 20 & 10 & 12 & 25 & 28 \\
\hline 4 & 7 & 12 & 15 & 6 & 10 & 15 & 20 & 10 & 15 & 20 & 31 \\
\hline 5 & 8 & 12 & 16 & 7 & 10 & 13 & 17 & 12 & 15 & 23 & 30 \\
\hline 3 & 10 & 13 & 19 & 5 & 6 & 8 & 14 & 13 & 18 & 25 & 31 \\
\hline
\end{tabular}

\begin{tabular}{|l|l|l|l|l|l|l|l|l|l|l|l|l|l|l|l|l|}
\hline Organism & \multicolumn{4}{|c|}{ CFX. } & \multicolumn{4}{|c|}{ CHS. } & \multicolumn{4}{|c|}{ SB.2 } \\
\hline ( $\boldsymbol{\mu} \mathbf{g} / \mathbf{m l}$ ) & $\mathbf{2 0}$ & $\mathbf{3 0}$ & $\mathbf{4 0}$ & $\mathbf{5 0}$ & $\mathbf{2 0}$ & $\mathbf{3 0}$ & $\mathbf{4 0}$ & $\mathbf{5 0}$ & $\mathbf{2 0}$ & $\mathbf{3 0}$ & $\mathbf{4 0}$ & $\mathbf{5 0}$ & $\mathbf{2 0}$ & $\mathbf{3 0}$ & $\mathbf{4 0}$ & $\mathbf{5 0}$ \\
\hline Cndida albicans & 12 & 15 & 18 & 22 & 0 & 4 & 9 & 12 & 0 & 5 & 8 & 10 & 0 & 4 & 7 & 12 \\
\hline
\end{tabular}

\begin{tabular}{|l|l|l|l|l|l|l|l|l|l|l|l|}
\hline \multicolumn{4}{|c|}{ SB.3 } & \multicolumn{4}{c|}{ SB.4 } & \multicolumn{4}{c|}{ SB.5 } \\
\hline $\mathbf{2 0}$ & $\mathbf{3 0}$ & $\mathbf{4 0}$ & $\mathbf{5 0}$ & $\mathbf{2 0}$ & $\mathbf{3 0}$ & $\mathbf{4 0}$ & $\mathbf{5 0}$ & $\mathbf{2 0}$ & $\mathbf{3 0}$ & $\mathbf{4 0}$ & $\mathbf{5 0}$ \\
\hline 0 & 8 & 10 & 13 & 0 & 10 & 14 & 17 & 10 & 16 & 20 & 24 \\
\hline
\end{tabular}

Ciprofloxacin-chitosan Schiff bases with molar ratios (0.05:1) SB.1, (0.1:1)SB.2, (0.25:1) SB.3, (0.5:1) SB.4 and (1:1)SB.5.

From these results, it can be generally indicated that the antibacterial activity of ciprofloxacin-chitosan Schiff bases is higher on gram positive bacteria comparing with that of ciprofloxacin itself. Schiff base (SB5) which formed by the condensation reaction of ciprofloxacin and chitosan with (1:1) molar ratio among all synthesized Schiff bases exhibited highest antibacterial activity especially against Staphylococcus aureus species at concentration $25 \mu \mathrm{g} / \mathrm{ml}$ compared with ciprofloxacin itself and all other Schiff bases. As indicated from this study, Schiff bases of ciprofloxacin and chitosan were exhibited a synergetic inhibitory effect against many species of bacteria especially Gram-positive ones.

The high antibacterial activity of ciprofloxacin-chitosan Schiff bases especially with (1:1) molar ratio shown in this study may be due to the synergistic effect of the mechanism of action against microorganisms of ciprofloxacin, chitosan and Schiff base.

Ciprofloxacin mechanism of action through the inhibition of bacterial gyrase, an enzyme involved in DNA replication, recombination and repair. By interfering with gyrase, ciprofloxacin arrest bacterial cell growth. Chitosan 
mechanism of action that owing to the electrostatic interaction between cationic components of chitosan $\left(\mathrm{NH}_{3}{ }^{+}\right.$ groups) and anionic residue of bacteria $\left(-\mathrm{COO}^{-}\right.$or $\mathrm{PO}_{4}^{-3}$ groups) by condensation amine group of chitosan and carbonyl group of ciprofloxacin, this can be explained on the basis that the $\pi$-electrons of imine groups $(\mathrm{C}=\mathrm{N})$ of Schiff bases enhance the lipophilicity of ciprofloxacin-chitosan Schiff bases which can facilitate penetration of the Schiff base molecules into the microbial cell membranes and then can disturb the respiration process of the cell and block the synthesis of proteins, which hinder the further growth of bacteria. On the other hand, molar ratio play a key role in change of the physicochemical properties and subsequently biological properties.

\section{Conclusion:-}

The antimicrobial activity of ciprofloxacin was enhanced by the condensation reaction with chitosan forming the corresponding Schiff base. The antimicrobial activity of ciprofloxacin was dependant on the degree of substitution of ciprofloxacin on chitosan. Schiff's base (SB5) which formed by the condensation reaction of ciprofloxacin with chitosan at ratio (1:1) exhibited the highest antibacterial activity especially against Staphylococcus aureus species at concentration $25 \mu \mathrm{g} / \mathrm{ml}$ compared with ciprofloxacin itself and all other Schiff bases. These results recommend the presented chemical route for modification of ciprofloxacin for medical applications.

\section{References:-}

1. Armstrong, G.L., Conn, L.A. and Pinner, R.W., Trends in infectious disease mortality in the united states during the 20th century. JAMA, 281, 61-66, 1999.

2. Sarkozy, G., Quinolones: a class of antimicrobial agents. Vet. Med. Czech, 46, (9-10): 257-274, 2001.

3. Soni, K., Fluoroquinolones: Chemistry \& Action - A Review. Indo Glob J Pharm Sci., 2(1): 43-53, 2012.

4. Adikwu, E. and Brambaifa, N., Ciprofloxacin induced chondrotoxicity and tendinopathy. American Journal of Pharmacology and Toxicology, 7 (3), 94-100 , 2012.

5. Uivarosi, V., Metal Complexes of Quinolone Antibiotics and Their Applications. Molecules, 18: 11153-11197, 2013.

6. Sharma, P.C., Jain, A. and Jain, S., Fluoroquinolone antibacterials: Areview on chemistry, microbiology and therapeutic prospects. Acta Pol Pharm Drug Res., 66(6): 587-604, 2009.

7. Gupta, Y. and Kapoor, S., Fluoroquinolones: a Pharmaceutical Review. Int J Pharm Sci Inven., 3 (9):66-71, 2014.

8. Andersson, M.I. and MacGowan, A.P., Development of the quinolones. J Antimic Chemo., 51: 1-11, 2003.

9. Jubie, S., Kalirajan, R. and Pavankumar, Y., Design, Synthesis and Docking Studies of a Novel Ciprofloxacin Analogue. Antimic Agent J Chem., 9(2): 980-987, 2012.

10. Rabbani, M.G., Islam, M.R., Ahmad, M. and Hossion, A.M.L., Synthesis of some NH-Derivatives of ciprofloxacin as antibacterial and antifungal agents. Bang J Pharm., 6: 8-13, 2011.

11. Qandil, A.M., Al-Zoubi, L.O., Al-Bakri, A.G., Amawi, H.A., Al-Balas, Q.A., Alkatheri A M and Albekairy AM. Synthesis, Antibacterial Evaluation and QSAR of $\alpha$-Substituted-N4-Acetamides of Ciprofloxacin and Norfloxacin. Antibiotics, 3: 244-269, 2014.

12. Sultana, N., Arayne, M.S., Rizvi, S.B. and Haroon, U., Synthesis, Characterization and Biological Evaluations of Ciprofloxacin Carboxamide Analogues Bull. Korean Chem. Soc., 32: 483-488, 2011.

13. Gesu, G.P., Marchetti, F., Piccoli, L. and Cavallero, A., Levofloxacin and Ciprofloxacin In Vitro Activities against 4,003. Clinical Bacterial Isolates Collected in 24 Italian Laboratories. Antimic agents and chem., 816819, 2003.

14. Jubie, S., Rajeshkumar, R., Yellareddy, B., Siddhartha, G., Sandeep, M., Surendrareddy, K., Dushyanth, H.S. and Elango, K., Microwave assisted synthesis of some novel benzimidazole substituted Fluoroquinolones and their antimicrobial evaluation. J. Pharm Sci \& Res., 2: 69-76, 2010.

15. Verma1, S., Sirbaiya, A.K. and Pandeya, S.N., Antimicrobial activity of Schiff base of ciprofloxacin. Pelagia Res Lib Pharm Sinica., 4(1): 1-9, 2013.

16. Pandeya, S.N., Ranjana, and Meena, K.Y., Synthesis and Antimicrobial Activity of Ciprofloxacin Schiff and Mannich bases. Int J Pharm Tech Res., 4:778-785, 2012.

17. Ketan, S.P., Jiten, C.P., Dholariya, H.R., Vishal, K.P. and Kanuprasad, D.P., Synthesis of Cu(II), Ni(II), Co(II), and Mn(II) Complexes with Ciprofloxacin and Their Evaluation of Antimicrobial, Antioxidant and AntiTubercular Activity. Open J Metal., 2: 49-59, 2012.

18. Rinaudo, M., Chitin and chitosan: Properties and applications. Prog. Polym. Sci., 31: 603-632, 2006.

19. Xia, W., Liu, P., Zhang, J. and Chen, J., Biological activities of chitosan and chitooligosaccharides. Food Hydr., xxx, 1-10, 2010. 
20. Jin, X., Wang, J. and Bai, J., Synthesis and antimicrobial activity of the Schiff base from chitosan and citral. Carbohyd Res., 344: 825-829, 2009.

21. Lin, S.B., Lin, Y.C. and Chen, H.H., Low molecular weight chitosan prepared with the aid of cellulase, lysozymeandchitinase: Characterisation and antibacterial activity. Food Chem., 116: 47-53, 2009.

22. Zhang, J., Xia, W., Liu, P., Cheng, Q., Tahirou, T., Gu, W. and Li, B., Chitosan Modification and Pharmaceutical/Biomedical Applications. Mar. Drugs., 8: 1962-1987, 2010.

23. Jiangtao, W. and Hedong, W., Preparation of soluble p-aminobenzoyl chitosan ester by Schiff's base and antibacterial activity of the derivatives. Int J BiolMacr., 48: 523-529, 2011.

24. Santosa, J.E. Dockala, E.R.E. and Cavalheirob, T.G., Synthesis and characterization of Schiff bases from chitosan and salicylaldehyde derivatives. Carbohydr. Polym., 60: 277-282, 2005.

25. Guinesi, L.S. and Cavalheiro, T.G., Influence of some reactional parameters on the substitution degree of biopolymeric Schiff bases prepared from chitosan and salicylaldehyde. CarbohydrPolym., 65: 557-561, 2006.

26. Takahashia T., Imaia, M., Suzukia, I. and Sawai, J., Growth inhibitory effect on bacteria of chitosan membranes regulated with deacetylation degree. Biochem. Engin J., 40: 485-491, 2008.

27. Sahooa, S., Kanti, C., Mishra, S.C. and Sharmistha., FTIR and XRD investigation of some fluoroquinolones. Int J Pharm Pharm Sci., 3: 165-170, 2011.

28. Lavertu, M., Xia, Z., Serreqi, A.N., Berrada M and Rodrigues A. A validatedH NMR method for the determinationof the degree of deacetylation of chitosan. J Pharm Biomed Anal., 32: 1149-1158, 2003.

29. Pandeya, S.N., Ranjana, Meena, K., Yadav., Synthesis and Antimicrobial Activity of Ciprofloxacin Schiff and Mannich bases. Int.J. PharmTech Res., 4(2): 778-785, 2012. 